\title{
Quantitative relation of urinary phenol levels to breathzone benzene concentrations: a factory survey
}

\author{
O INOUE, ${ }^{1,2}$ K SEIJI, ${ }^{1,2}$ M KASAHARA, ${ }^{2}$ H NAKATSUKA, ${ }^{2}$ T WATANABE, ${ }^{2}$ \\ S-G YIN, ${ }^{3}$ G-L LI, ${ }^{3}$ C JIN, ${ }^{3}$ S-X CAI, ${ }^{3}$ X-Z WANG, ${ }^{4}$ M IKEDA ${ }^{2}$ \\ From the Center of Occupational Medicine, ${ }^{1}$ Tohoku Rosai Hospital, and Department of Environmental \\ Health, ${ }^{2}$ Tohoku University School of Medicine, Sendai 980, Japan, Institute of Health, ${ }^{3}$ China Centre for \\ Preventive Medicine, Beijing, and Anhui Province Institute for Prevention and Treatment of Occupational \\ Diseases, ${ }^{4}$ Hefei, China
}

ABSTRACT Urine samples were collected from 64 men and 88 women in shoe factories and printing plants at the end of a seven hour day shift in the latter half of a week in spring. Urine samples were also taken from 43 men and 88 women in the same factories but who were not exposed to solvents. Exposure to benzene during the shift was monitored by passive dosimeters. Both phenol in urine and benzene in activated carbon were analysed with FID gas chromatographs. The urinary concentrations of phenol were linearly related to the time weighted average concentrations of benzene in the breathzone air; the variation was so small that those exposed to $10 \mathrm{ppm}$ benzene could be separated from the non-exposed at least on a group basis when the phenol concentration was corrected either for creatinine concentration or for specific gravity. The urinary phenol concentrations corresponding to $10 \mathrm{ppm}$ benzene were $47.5 \mathrm{mg} / \mathrm{l}$ (as observed), $57.9 \mathrm{mg} / \mathrm{g}$ creatinine, or $46.6 \mathrm{mg} / \mathrm{l}$ (specific gravity 1.016).

Benzene is considered to be a cause of human leukaemia $^{1}$ and occupational as well as nonoccupational exposure to this chemical has been a focus of keen attention. Among the biological indicators of exposure to benzene, urinary phenol has been most frequently used although it may be inferior to benzene in blood in its sensitivity and specificity, ${ }^{23}$ probably because urine is apparently much more readily available from factory workers than venous blood, and this is especially so in the case of the general population. The existing data on the quantitative relation between exposure to benzene and urinary phenol excretion are, however, usually hampered by the technical limitations prevailing at the time of the study such as the low specificity of urinary phenol determination, the inability to measure average exposure during work, the small number of subjects, or a combination of these factors. ${ }^{2}$

The present study was initiated to establish the quantitative exposure excretion relation, using passive samplers to determine the time weighted average exposure intensity of exposure to benzene and FID gas chromatography for the specific mea-

Accepted 21 January 1986 surement of phenol in urine. The results of studie with similar methodology have been described for toluene hippuric acid/o-cresol ${ }^{4}$ and tetrachloroethylene total trichloro compounds. ${ }^{5}$

\section{Materials and methods}

\section{EXAMINEES}

The factory survey was conducted in the latter half of a week in spring. The workers exposed to benzene were 64 men (aged $26.9 \pm 8.4$ years as arithmetic mean \pm arithmetic standard deviation (AM \pm ASD)) and 88 women (29.9 \pm 8.5 years) in five workshops in two shoe factories and two small printing plants. Control subjects were 43 men $(39.3 \pm 11.9$ years) and 88 women $(26.9 \pm 8.4$ years) who worked in the same factories but had not been exposed to solvents. Those under medical treatment with drugs were excluded.

COLLECTION AND ANALYSES OF URINE SAMPLES Each subject was asked to pass urine at about 1300 . The urine sample for analysis was collected at about $\underset{<}{\sigma}$ 1500 when the seven hour shift was over and the 0 urinary phenol concentration was expected to reach a maximum; the urine was kept at $-80^{\circ} \mathrm{C}$ before analy- 
sis. Phenol concentration was determined gas chromatographically by the method previously described for o-cresol ${ }^{4}: 1 \mathrm{ml}$ of urine was mixed with $0.5 \mathrm{ml} 15 \%$ $\mathrm{HCl}$ and heated for one hour for acid hydrolysis. Then, 3,5-xylenol (either 1.25 or $5 \mu \mathrm{g}$ ) was added as an internal standard and the mixture was extracted with $2 \mathrm{ml}$ of carbon disulphide. The organic phase was treated with sodium sulphate for desiccation. An aliquot of $1 \mathrm{ml}$ was transferred to a test tube and the volume was reduced to about one twentieth or less under a stream of nitrogen. An aliquot of 1 to $5 \mu \mathrm{l}$ was injected into a Hitachi FID gas chromatograph (model 163) equipped with 60-80 mesh KG-02 on Uniport HP glass columns $(3 \mathrm{~mm}$ in inner diameter and $5 \mathrm{~m}$ in length). The injection port and the oven were heated at $210^{\circ} \mathrm{C}$ and $180^{\circ} \mathrm{C}$, respectively. The carrier gas (nitrogen) was allowed to flow at a rate of $30 \mathrm{ml} / \mathrm{min}$ and the supplies of hydrogen and air to the detectors were at $1.0 \mathrm{~kg} / \mathrm{cm}^{2}$ and $1.5 \mathrm{~kg} / \mathrm{cm}^{2}$, respectively. Under such conditions phenol was clearly separated from o-, $\mathrm{m}$-, and p-cresols on the chromatogram. The phenol concentration was expressed as a measured value, as the ratio to the creatinine concentration, ${ }^{6}$ or after correcting to the specific gravity of the urine of $1 \cdot 016 .^{7}$ The creatinine concentration was measured colorimetrically ${ }^{8}$ and the specific gravity by refractometry.

\section{DETERMINATION OF BENZENE CONCENTRATION IN BREATHZONE AIR}

Badge type passive samplers with $\mathrm{K}$-filter $1600^{9}$ were used for personal breathzone air sampling to measure the time weighted average exposure (from about 0800 to about 1500 ). The precise duration of sampling was recorded for each individual or workshop. After exposure, the activated carbon filters were brought to an analytical laboratory distant from the survey sites within two days and kept refrigerated before analysis (within two weeks). ${ }^{10}$

An additional study disclosed that, when kept at $4^{\circ} \mathrm{C}$, there was no significant $(\mathrm{p}<0 \cdot 10)$ loss in benzene on the carbon over a six month period. The gas chromatrographic analysis of the carbon disulphide extract showed that the major component of the solvent vapour in the air was benzene; other contaminants such as toluene, $n$-hexane, or ethyl acetate were detected at trace level (less than $5 \%$ of that of benzene at most) only occasionally. When the benzene concentrations were expressed on a group basis, a $\log$ normal distribution was assumed. ${ }^{11}$

\section{Results}

PHENOL CONCENTRATIONS IN THE URINE OF THE NON-EXPOSED SUBJECTS

Phenol concentrations in the control urine samples accumulated in the range of $0-10 \mathrm{mg} / \mathrm{l}$ in the cases of observed values and after correction for a specific gravity $(1.016)$ or $1-10 \mathrm{mg} / \mathrm{g}$ when corrected for creatinine. A skew towards higher levels was observed suggesting a log normal rather than a normal distribution. Accordingly, geometric means (GMs) and geometric standard deviations (GSDs) were calculated with an assumption of a log normal distribution; the results are summarised in table 1 . The difference in the GMs between the two sexes was small even though statistically significant in some cases. When the results for the two sexes were combined, the GMs were either below $10 \mathrm{mg} / \mathrm{l}$ (the observed value and the value corrected for a specific gravity) or $10 \mathrm{mg} / \mathrm{g}$ (the value corrected for creatinine).

\section{CORRELATION BETWEEN BENZENE}

CONCENTRATIONS IN BREATHZONE AIR

AND PHENOL CONCENTRATIONS IN URINE

When the exposed workers were grouped by workshop and by sex, and benzene GM and phenol GM compared (table 2), the range of both breathzone benzene concentrations and urinary phenol concentrations was wide but the former were generally paralleled by the latter even though the number of workers in some workshops was small (workshops A and D, for example). It should also be noted that GSDs were greater than 2 in several cases, indicating that the exposures, even in a single workshop, might vary

Table 1 Phenol concentration in urine samples from non-exposed subjects

\begin{tabular}{|c|c|c|c|c|}
\hline \multirow[b]{2}{*}{ Non-exposed subject } & \multirow[b]{2}{*}{ No of examinees } & \multirow[b]{2}{*}{$\begin{array}{l}\text { Observed valuet } \\
(\mathrm{mg} / \mathrm{l})\end{array}$} & \multicolumn{2}{|c|}{ Value $\dagger$ corrected for } \\
\hline & & & $\begin{array}{l}\text { Creatinine } \\
(\mathrm{mg} / \mathrm{g})\end{array}$ & $\begin{array}{l}\text { Specific gravity§ } \\
(\mathrm{mg} / \mathrm{l})\end{array}$ \\
\hline $\begin{array}{l}\text { Men + women } \\
\text { Men } \\
\text { Women }\end{array}$ & $\begin{array}{r}131 \\
43 \\
88\end{array}$ & $\begin{array}{l}6.91(2.622) \\
7.65(2.861) \\
6.57(2 \cdot 511)\end{array}$ & $\begin{array}{c}8.63(1.921) \\
10.27(1.845)^{*} \\
7.93(1.932)\end{array}$ & $\begin{array}{l}7.10(1.983) \\
9.09(1.892)^{* *} \\
6.29(1.968)\end{array}$ \\
\hline
\end{tabular}

${ }^{*}$ and ${ }^{* *}$ indicate that the difference between the two sexes is statistically significant $\left({ }^{*} p<0.05,{ }^{* *} p<0.01\right)$.

+ Geometric mean (geometric standard deviation).

†Phenol concentration divided by creatinine concentration.

$\S$ Phenol concentration adjusted to a specific gravity of 1.016 . 
Table 2 Phenol concentration in the urine of workers exposed to benzene in various workshops

\begin{tabular}{|c|c|c|c|c|c|}
\hline \multirow[b]{3}{*}{ Workshop } & \multirow[b]{3}{*}{$\begin{array}{l}\text { No of } \\
\text { workers }\end{array}$} & \multirow[b]{3}{*}{$\begin{array}{l}\text { Benzene concentration } \\
\text { in breathzone air } \\
(p p m)\end{array}$} & \multicolumn{3}{|c|}{ Phenol concentration* } \\
\hline & & & \multirow[b]{2}{*}{$\begin{array}{l}\text { Observed value } \\
\text { (mg/l) }\end{array}$} & \multicolumn{2}{|c|}{ Value corrected for } \\
\hline & & & & $\begin{array}{l}\text { Creatinine } \\
(\mathrm{mg} / \mathrm{g})\end{array}$ & $\begin{array}{l}\text { Specific gravity } \ddagger \\
(m g / l)\end{array}$ \\
\hline \multicolumn{6}{|l|}{ Men: } \\
\hline $\begin{array}{l}\text { A } \\
\text { B } \\
\text { C } \\
\text { D } \\
\text { E }\end{array}$ & $\begin{array}{c}3 \\
24 \\
20 \\
2 \S \\
15\end{array}$ & $\begin{array}{c}1 \cdot 0(1 \cdot 000) \\
11 \cdot 1(2 \cdot 398) \\
32 \cdot 6(1 \cdot 421) \\
7,76 \\
60 \cdot 2(1 \cdot 282)\end{array}$ & $\begin{array}{c}12(2 \cdot 798) \\
32(2 \cdot 145) \\
106(1 \cdot 784) \\
16,85 \\
277(1.657)\end{array}$ & $\begin{array}{c}7(1 \cdot 812) \\
42(2 \cdot 125) \\
147(1.498) \\
15,160 \\
313(1 \cdot 320)\end{array}$ & $\begin{array}{c}8(1.869) \\
34(2 \cdot 321) \\
119(1.456) \\
16,136 \\
206(2 \cdot 259)\end{array}$ \\
\hline \multicolumn{6}{|l|}{ Women: } \\
\hline $\begin{array}{l}\text { A } \\
\text { B } \\
\text { C } \\
\text { D } \\
\text { E }\end{array}$ & $\begin{array}{c}1 \S \\
19 \\
37 \\
2 \S \\
29\end{array}$ & $\begin{array}{c}1 \\
18 \cdot 1(2 \cdot 792) \\
42 \cdot 4(2 \cdot 485) \\
5,37 \\
76 \cdot 4(1 \cdot 576)\end{array}$ & $\begin{array}{c}3 \\
76(3.945) \\
134(2 \cdot 235) \\
5,100 \\
319(2 \cdot 178)\end{array}$ & $\begin{array}{c}5 \\
102(3.041) \\
169(2 \cdot 143) \\
6,165 \\
427(1 \cdot 783)\end{array}$ & $\begin{array}{c}4 \\
77(2 \cdot 818) \\
124(2 \cdot 116) \\
4,114 \\
315(1.662)\end{array}$ \\
\hline
\end{tabular}

*Geometric mean (geometric standard deviation).

†Phenol concentration divided by creatinine concentration.

$\$$ Phenol concentration adjusted to a specific gravity of 1.016 .

§Individual values shown.

depending on the individual worker. Accordingly, further comparisons between the two measurements were made on an individual basis using scatter diagrams as shown in the figure. Despite the difference in the maximum exposure between the sexes (some of the female workers were exposed well above $100 \mathrm{ppm}$ whereas exposure of male workers never exceeded this concentration), the correlation appeared to be similar for the two sexes. It should also be noted that the variation around the regression was smaller in every case when the phenol concentrations were corrected for creatinine concentration than when observed phenol concentrations or specific gravity corrected phenol concentrations were used.

The correlation coefficients are summarised in table 3. The correlation was significant $(p<0.01)$ and the value of the coefficient was about 0.8 or higher in all cases; the largest coefficient was obtained when phenol concentrations were corrected for creatinine $\vec{\theta}$ concentration. The intercepts on the phenol axs (table 3) were essentially the same as the GMs for the non-exposed subjects (table 1), and rather small bu comparison with the corresponding slopes (equiv alent to 1 to $3 \mathrm{ppm}$ benzene exposure). As both the

Table 3 Correlation between breathzone benzene concentration and urinary phenol concentration

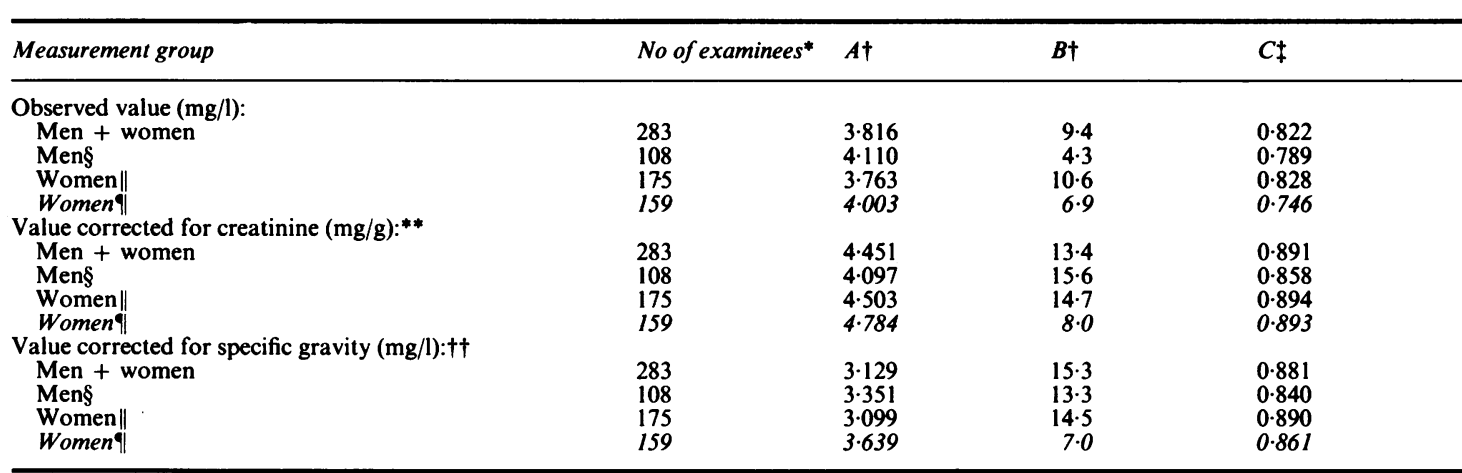

*Including non-exposed subjects (43 men and 88 women).

†Slope (A) and the intercept on the $\mathrm{Y}$ axis (B) in the figure as: $\mathrm{Y}=\mathrm{AX}+\mathrm{B}$, where $\mathrm{Y}$ is phenol concentration (unit; as described in the table) in urine and $X$ is time weighted average benzene exposure concentration (ppm).

+ Correlation coefficient. $p<0.01$ for all correlation coefficients.

$\S$ Exposed up to $92 \mathrm{ppm}$.

IExposed up to $210 \mathrm{ppm}$.

Women exposed to less than $100 \mathrm{ppm}$

** Phenol concentration divided by creatinine concentration.

++ Phenol concentration adjusted for a specific gravity of 1.016 . 


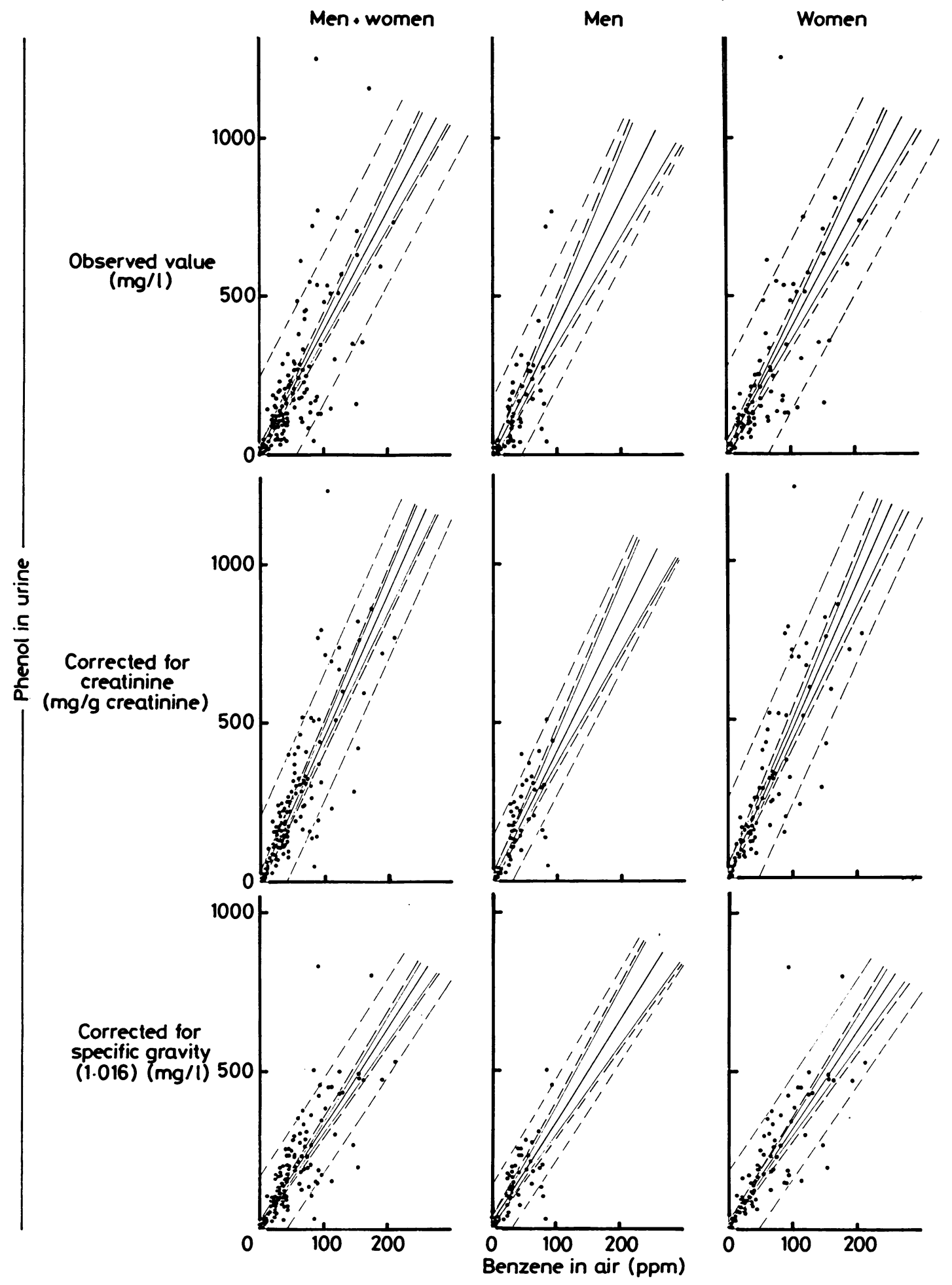

Relation between benzene in breathzone air and phenol in urine. Points indicate individual values. Lines and curves are calculated regression line (solid line in centre), $95 \%$ confidence ranges of sample means (thin curves), $95 \%$ confidence ranges of the regression line (the broken lines), and $95 \%$ confidence ranges of the individual samples (the outmost broken lines). 
intercept and the slope were similar in men and women, it was clear that the regression lines did not vary between the two sexes. This was the case even when women exposed to less than $100 \mathrm{ppm}$ were selected (taking the difference in maximum exposure levels between the sexes into consideration).

\section{Discussion}

The present study clearly demonstrates that the phenol concentration in urine (collected at around 1500 in the latter half of the week) is proportional to the benzene concentration in breathzone air (expressed as a time weighted average) at least up to $200 \mathrm{ppm}$. The slope of the regression line obtained in the present study -3 to $4 \mathrm{mg}$ phenol/1 urine (or $\mathrm{g}$ creatinine)/ppm benzene-was larger than the values reported in some previous studies. For example, a slope of 0.33 (unit: $\mathrm{mg}$ phenol/litre urine/ppm $\times$ hour benzene) was calculated by Lauwerys ${ }^{2}$ primarily from the data of Rainsford and Lloyd Davies, ${ }^{7}$ Berlin et al, ${ }^{12}$ and Sherwood, ${ }^{13}$ which is equivalent to $2.3 \mathrm{mg} / 1 / \mathrm{ppm}$ when a seven hour exposure is assumed. Most of the high values cited in the calculations of Lauwerys were, however, derived from workers who spent substantial periods in uncontaminated air, ${ }^{7}$ whereas spot workroom air samples were used for benzene determination. Thus the intensity of exposure might have been overestimated. In another study in which phenol concentrations (measured colorimetrically by the Theis-Benedict method) were adjusted to a specific gravity of 1.024 a regression line with a slope estimated to be $7.0 \mathrm{mg} / 1 / \mathrm{ppm}$ was found ${ }^{14}$ Adjusting the specific gravity to 1.016 gives a slope of $4.7 \mathrm{mg} / 1 / \mathrm{ppm}$, a value slightly higher than the present results. The data from Pagnotto and Bethlehem Steel as cited by the National Institute for Occupational Health and Safety gave a slope of 7.2 and $3.9 \mathrm{mg} / 1 / \mathrm{ppm}$, respectively, assuming a linear regression. ${ }^{15}$ Assuming that urinary phenol concentrations were adjusted to a specific gravity of 1.024 by Pagnotto, readjustment to 1.016 results in a slope of $4.8 \mathrm{mg} / 1 / \mathrm{ppm}$. If cases with "normal" phenol concentrations are excluded from Bethlehem Steel data the slope becomes $3.8 \mathrm{mg} / \mathrm{l} / \mathrm{ppm}$.

One of the critical points in evaluating urinary phenol as a biological estimator of benzene exposure is to determine whether the estimator can separate those exposed to benzene at a given occupational exposure limit such as $10 \mathrm{ppm}$ from those not exposed. Comparison of the lower $95 \%$ confidence range of the mean phenol concentrations at $10 \mathrm{ppm}$ benzene (figure) and the upper $95 \%$ confidence range of the phenol concentrations in the non-exposed subjects as calculated by $G M \times(G S D)^{2}$ (table 1$)$ shows that the former was larger than the latter in men, women, and men + women when phenol concen- $\overline{ }$ trations were corrected for either creatinine or a specific gravity, although this was not the case with observed (uncorrected) phenol concentrations. For $\stackrel{?}{\circ}$ example, the lower $95 \%$ confidence value (using phe- $\frac{\overrightarrow{\vec{D}}}{\overrightarrow{\mathrm{O}}}$ nol concentrations corrected for creatinine) for men $\frac{\overrightarrow{0}}{}$ + women was $45.1 \mathrm{mg} / \mathrm{g}$ creatinine: the correspond- $\frac{\bar{O}}{\mathrm{O}}$ ing upper $95 \%$ confidence limit for the non-exposed $\overline{\bar{\omega}}$. men + women was $31.9 \mathrm{mg} / \mathrm{g}$ creatinine. Thus it is $\widetilde{\mathbb{}}$ reasonable to conclude that the separation of those $\varrho$ exposed to $10 \mathrm{ppm}$ benzene from those not exposed is $ळ$ possible at least on a group basis, so far as the effects $\vec{O}$ of medication ${ }^{16-18}$ are excluded. It is clearly impossible to make the separation on an individual basis as the wide $95 \%$ confidence ranges indicate (figure).

No follow up of phenol excretion was made in the $\frac{\mathbb{D}}{3}$ present study to cover the entire period of phenol excretion. It is possible, however, to make a cross $\stackrel{\omega}{\omega}$ sectional balance study between the amount of $\overrightarrow{0}$ benzene absorbed and the excretion of phenol in urine 8 at the end of work with exposure to benzene at, $N$ say, $10 \mathrm{ppm}$, using three assumptions; that about $\frac{}{2}$ $50 \%$ of inhaled benzene is absorbed through the lungs (by analogy with toluene ${ }^{19}$ ) and that the rates of respiration and urinary excretion under the ${ }^{+}$ conditions studied are $15 \mathrm{l} / \mathrm{min}$ and $1 \mathrm{ml} / \mathrm{min}$, 黑 respectively. The input will be $10 \mathrm{ppm}(=31.9 \vec{A}$ $\left.\mathrm{mg} / \mathrm{m}^{3}\right) \times 15 \times 10^{-3}\left(\mathrm{~m}^{3} / \mathrm{min}\right) \times 0.5=0.23925 \mathrm{mg} / \mathrm{m}^{3}{ }_{0}$ whereas the output into urine in the form of phenotiss. $38.16 \mathrm{mg} / 1 \times 1 \times 10^{-3} 1 / \mathrm{min}=0.003816 \mathrm{mg} / \mathrm{min}$ grO $0.003167 \mathrm{mg} / \mathrm{min}(0.03816 \mathrm{mg} / \mathrm{min} \times 78.11 / 94 \cdot 11)$ ws benzene, where 78.11 and 94.11 are molecularō weight of benzene and phenol, respectively. Thus at the end of the workshift about $13 \% \propto$ $(=0.04755 / 0.23925 \times 100)$ of benzene absorbed $\overrightarrow{\vec{A}}$ through the lungs will be converted to phenol and $\rightrightarrows$ excreted into the urine.

Further analyses of the urine samples are currentlyọ in progress for polyhydroxylated benzene metabolites such as catechol and hydroquinone, possible con- $\frac{\mathbb{D}}{3}$ tributors to the development of benzene toxicity ${ }^{20-22}$ ? to correlate the urinary concentrations with the 3 . intensity of benzene exposure.

We thank the Health Bureau of Hefei City and $\operatorname{Dr}_{0}$ S-L Fu, Ms R-G Zhang, Mr W-G Wu, Ms G-F Cui, Mr L-H Zai, Ms J-F Wan, and Ms L-S Hong for their supportive cooperation in the field investigation.

Requests for reprints to: Professor M Ikeda.

\section{References}

1 International Agency for Research on Cancer. Benzene. IARCO monographs on the evaluation of the carcinogenic risk of chemicals to humans 1982;29:99-148.

2 Lauwerys R. Industrial health and safety: human biological mon- 
itoring of industrial chemicals 1. Benzene. Luxembourg: Commission of the European Communities, 1979:18-25.

3 Berlin RE, Logan DC. International seminar on the assessment of toxic agents at the workplace. Roles of ambient and biological monitoring, Luxembourg, 8-12 December, 1980. Int Arch Occup Environ Health 1982;50:197-207.

4 Hasegawa K, Shiojima S, Koizumi A, Ikeda M. Hippuric acid and o-cresol in the urine of workers exposed to toluene. Int Arch Occup Environ Health 1983:52:197-208.

5 Ohtsuki T, Sato K, Koizumi A, Kumai M, Ikeda M. Limited capacity of humans to metabolize tetrachloroethylene. Int Arch Occup Environ Health 1983;51:381-90.

6 Jackson S. Creatinine in urine as an index of urinary excretion rate. Health Phys 1966;12:843-50.

7 Rainsford SG, Lloyd Davies TA. Urinary excretion of phenol by men exposed to vapour of benzene: a screening test. $\mathrm{Br} J$ Ind Med 1965;22:21-6.

8 Ikeda M, Ohtsuji $\mathrm{H}$. Hippuric acid, phenol and trichloroacetic acid levels in the urine of Japanese subjects with no known exposure to organic solvents. Br J Ind Med 1969;26:162-4.

9 Hirayama T, Ikeda M. Applicability of activated carbon felt to the dosimetry of solvent vapor mixture. Am Ind Hyg Assoc J 1979;40:1091-6.

10 Ikeda M, Kumai M, Aksoy M. Application of carbon felt dosimetry to field studies distant from analytical laboratory. Ind Health 1984;22:53-8.

11 Ikeda M, Ohtsuki T. Exposure concentration versus environmental concentration: a field survey in organic solvent workplaces. Tohoku J Exp Med 1985;146:225-35.

12 Berlin M, Fredga K, Gage JC, Lagesson V, Reitalu J, Tunek A. 1975. Cited from Lauwerys, $1979 .{ }^{2}$
13 Sherwood RJ. Evaluation of exposure to benzene vapour during the loading of petrol. Br J Ind Med 1972;29:65-9.

14 Walkley JE, Pagnotto LD, Elkins HB. The measurement of phenol in urine as an index of benzene exposure. Am Ind Hyg Assoc $J$ 1961;22:362-7.

15 National Institute of Occupational Safety and Health. Criteria for a recommended standard: occupational exposure to benzene. Washington: US Department of Health, Education and Welfare, 1974: tables XII-10 and 12, pp 131 and 133.

16 Fishbeck WA, Langer RR, Kociba RJ. Elevated urinary phenol levels not related to benzene exposure. Am Ind Hyg Assoc J 1975;36:820-4.

17 Kociba RJ, Kalnins RV, Wade CE, Garfield EL, Fishbeck WA Elevated phenol levels in beagle dogs treated with salol. $\mathrm{Am}$ Ind Hyg Assoc J 1976;37:183-91.

18 Eikmann T, Gabriel M, Lenaerts-Langanke M, Prajsnar D. Die Phenolauascheidung bei erwachsenen Menschen in Abhängigkeit von Medikamenteneinnahme und Krankheitsbild. Zentralbl Arbeitsmed 1983;33:40-8.

19 World Health Organisation. Recommended health-based limits in occupational exposure to selected organic solvents: toluene. Geneva: WHO, 1981:8. (WHO technical report series 664.)

20 Greenlee WF, Sun JD, Bus JS. A proposed mechanism of benzene toxicity: formation of reactive intermediates from polyphenol metabolites. Toxicol Appl Pharmacol 1981;59:187-95.

21 Bolcsak LE, Nerland DE. Inhibition of erythropoiesis by benzene and benzene metabolites. Toxicol Appl Pharmacol 1983 69:363-8.

22 Gad-El-Karim MM, Ramanujam S, Ahmed AE, Legator MS. Benzene myeloclastogenicity: a function of its metabolism. Am Ind Hyg Assoc J 1985;7:475-84. 